\title{
Translating Place Identity into Transmedia Communication Systems: Communication Design Process and Methods
}

\author{
Scuri, Sabrina ${ }^{a}$; Chiodo, Elisa $^{\mathrm{b}} \&$ Calabi, Daniela ${ }^{\mathrm{c}}$ \\ a Dipartimento di Design - Politecnico di Milano, Italia. sabrina.scuri@polimi.it, \\ b Dipartimento di Design - Politecnico di Milano, Italia. elisa.chiodo@polimi.it, \\ c Dipartimento di Design - Politecnico di Milano, Italia. daniela.calabi@polimi.it.
}

\begin{abstract}
The paper discusses the role of Communication Design in promoting cultural heritage and enhancing local identity. It deals with the need of designing communication systems able to increase people's understanding and engagement with a given place.

We argue that a communication strategy able to leverage on both tangible and intangible aspects of place identity leads to a more mindful tourism consumption, and it is a means to strengthen citizens' sense of belonging as well. To this aim, we highlight the importance of blending cultural information with technologies and languages to make the exploration of a place more accessible and meaningful. Specifically, our research focuses on the contribution given by "immersive languages" to strengthen the relation between human and environment.
\end{abstract}

Here, great emphasis is put on the transformative function of design that lies in the ability of translating and transferring intangible elements into digital products and communication systems. As an example of this translating process, the paper presents a didactic experience with a class of MSc students in Communication Design. They were asked to design transmedia communication systems for exploring the city of Milan through literary paths. Every transmedia system aims to represent the specific point of view of an author and the context in which he lived and worked. The main project goal was to create a complex mixing of media, languages and medium, in order to engage users on different channels, foster the exploration of the city and support the development of new knowledge about its identity.

The paper will describe each step of the design process focusing on approach and methods adopted to foster and nurture the projects development.

Keywords: Communication Design, Place Identity, Design Process, Design Methods, Transmedia Systems. 


\section{Introduction}

People's identity has been always bound up with the sense of belonging to a place but today this bond is progressively vanishing. The 'local dimension', which represents the features of places and their communities, is threatened by globalization and by cultural and economic interconnections.

The phenomenon observed by EZIO MANZINI in 2004, that is to say the «inclinations towards turning what remains of traditions and landscapes into a show for tourist purposes (the tourist-related 'supermarket type' of localism, which is just another side of the standardising aspect of globalisation, from which there is the desire to break away)» (Manzini, 2004, p. 103), is still ongoing. The commodification of territories - which are presented to the eyes of tourists according to the diffused stereotypes - is leading towards a progressive disappearance of local identity. It is important to notice that this process affects the image of places not only from an outside perspective (tourists' perspective) but also and especially from the inside perspective (locals' perspective). Inhabitants start to feel they are part of a 'staged authenticity' (MacCannell, 1973) - a term that refers to the staging of local culture to create an impression of authenticity for a tourist audience. Locals can refuse to identify themselves with that image or start to mirror it (Maoz, 2006); in both cases, the result is a decreased sense of belonging.

The safeguarding and the enhancement of local identity and cultural heritage is a crucial issue in our contemporary society. They are indeed considered key drivers for social cohesion and economic growth, as it is pointed out in the introduction to the Work Programme 2014 - 2015 Europe in a changing worldinclusive, innovative and reflective Societies which claims: «In challenging times for its internal coherence, Europe should improve the understanding of its cultural heritage and of its identities in order to strengthen cohesion and solidarity and to encourage modern visions and uses of its past. [...] In these efforts, new technologies and digital cultural heritage should play an important innovative role as they enable new and richer interpretations of our common European culture while contributing to sustainable economic growth» (European Commission, 2013, p. 5). In the Work Programme, the European Commission makes explicit reference to the role of cultural heritage in tourism industry. In other words, it seems that tourist promotion could be also a means to communicate and describe a place to its inhabitants.

Understanding cultural heritage has always been a travel motivation but, as pointed out by RICHARDS (2014), recently the concept of "culture" has been reframed. He observes a shift from tangible to intangible culture and a consequent decline of the traditional cultural consumption model. New technologies and digital media play an important role in allowing the access to this kind of 'intangible culture' because they offer several opportunities to explore, understand and engage with a place and its intangible aspects. Consequently, a communication project should be thought and designed in terms of system as it is able to create different touch points between people, places and culture.

In this context, the design disciplines should have a crucial role since, according to the words of RAFFAELLA FAGNONI, design «uses technologies and chooses according to its own "sensitivity" [...] in order to diffuse meaning and cause the project, the design to become not an added value, but a meaning, a concept implicit in things and products [...] free from restrictions and cliché» (Fagnoni, 2004, p. 222). Therefore, we argue that design can be a bridge able to develop a deep and extended knowledge of territories, both in a local and global context.

In the following pages we will describe how the transformative power that lies behind design process allows to re-connect the traces of the past to our present and future. Specifically, the paper focuses on the contribution of communication design in developing models (communication systems and formats) to exploit different media channels and technologies in order to shape and disseminate intangible culture, as 
well as to foster the understanding and the sustainable enhancement of local resources, not only physical but also (and especially) socio-cultural.

\section{Design transformative function: formats and tools to "translate" the intangible culture}

As stated above, to foster a deep understanding of places a communication project cannot focus only on promoting physical resources but also (and especially) it should describe the intangible aspects of local identity. Basically, a communication project should present and describe a Cultural Landscape ${ }^{45}$, which is made by the combination of both tangible and intangible cultural values (Mitchell et al., 2009). Indeed, as pointed out in the EUROPEAN LANDSCAPE CONVENTION, Landscape is «an essential component of people's surroundings, an expression of the diversity of their shared cultural and natural heritage, and a foundation of their identity» (Council of Europe, 2000, p. 11).

Considering that these cultural contents (those that enable to reveal a Landscape) have also an intangible character and/or can relate to abstract concepts, they could need to be transformed (or somehow "translated") into other forms (visual, for instance) in order to become comprehensible. To this aim, different media content (photos, videos, audios) can be combined in different multimedia package (Zerba, 2004) and delivered through several communication channels.

As already pointed out, new technologies and digital media offer a bunch of opportunities to access, understand and engage with a place and its intangible culture. The ongoing developments that involve the current media context (e.g. the upgrading of network capacity and the development of more sophisticated programming languages) are leading toward multimedia convergence fostering the combination, overlapping and blending of different media content (Taiuti, 2005). Consequently, we observe the rise of several hybrid formats which exploit the possibilities offered by digital technology to provide users with new opportunities of engaging with content. We used the term 'hybrid' to describe these formats because they combine traditional communication forms, like the video documentary or the journal article, with the features of digital media (Gifreu, 2011; Lassila-Merisalo, 2014; Grabowicz et al., 2014) - e.g. interactivity, multimedia, a nonlinear structure, etc.

The understanding of all of these "tools" is crucial to design an effective communication strategy because they strongly affect our media consumption and, as it will be better described in the following paragraphs, allow to provide users with the meaningful experiences they are seeking. Today, people want to be completely absorbed by the media contents provided, and expect to interact naturally and smoothly with them; in other words, their cognition and perceptions should be entirely engrossed by the experience. For this reason, we suggest that the bond between people and places can be strengthened, or even created, if it enables to make experience of the Cultural Landscape ('experience' is here understood, according to Aristotle's definition, as a type of knowledge based on sensible perception). Considerable efforts have been made, especially in tourism industry, in order to understand the role of experience in shaping the relationship between people and places. From this perspective, one of the most interesting contributions is a work by FABIO FORLANI that looks at the tourist experience through the PINE AND GILMORE's four realms of experience (Pine and Gilmore, 1999). Specifically, in his model, FORLANI considers the aesthetic dimension as the necessary condition to gain a richer tourist experience (Forlani, 2004,).

45 "Cultural landscape" is here understood according to UNESCO's definition: «Cultural landscapes are cultural properties and represent the 'combined works of nature and of man' designated in Article 1 of the Convention. They are illustrative of the evolution of human society and settlement over time, under the influence of the physical constraints and/or opportunities presented by their natural environment and of successive social, economic and cultural forces, both external and internal» (UNESCO, 2013, p. 14). 
Representing cultural landscape can be conceived, indeed, as an aesthetic work ${ }^{46}$ - which is, in a broader sense, as a work of Design (Griffero, 2010) - because it involves the ability to turns cultural content into aesthetic experiences. Therefore, we argue that to promote a place and foster the knowledge about its identity we have to develop sensorially rich mediated environments. For this reason, communication designers should focus on the way contents are displayed, as well as on how and when users interact with them, in order to create a complex mixing of media, languages and medium, able to create different touch points between people, places and culture.

\subsection{Immersive languages for translating cultural content}

According with FORLANI, tourism is always a comprehensive aesthetic experience that allows people to immerse themselves in an event or environment (Forlani, 2004) therefore, the need of 'immersion' seems to be the driving force for experiencing a place. This statement is supported by ORTOLEVA in his book Il secolo dei media. Riti, abitudini, mitologie. The author claims, indeed, that in tourism industry the demand for experience is precisely a demand for immersion (Ortoleva, 2009). The connection between experience and immersion is also highlighted by FRANCESCO D'ORAZIO (2003). He points out that the term 'experience' is strictly connected to the idea of 'immersion' because both of them arise from the interaction between space and body. To be more precise, he argues that experience is a quality of immersion. Starting from these assumptions, we can reasonably hypothesize that a communication project able to foster the feeling of immersion could meet the tourists' demand for experience.

But immersion is a quite tricky concept to deal with because can be addressed by two divergent perspectives. On the one hand, there's the technology-driven viewpoint, which basically considers immersion as the result of using specific immersive technologies and is by far the most widespread approach to the topic. People usually relate immersion to Virtual Reality which, in its turn, uses the term to indicate what the technology delivers from an objective point of view (Slater, 2003). On the other hand, there is a second school of thought which considers immersion in terms of cognitive and perceptual absorption - a kind of experience that «takes over all of our attention, our whole perceptual apparatus» (Murray, 1997, p. 98). In cinema, for instance, LAURENT JULLIER (1997) defines figures de l'immersion those representations aimed at eliciting in the audience the sensation of 'being surrounded by a sea of sensations'. This non-technical perspective relates to the way users engage with content and is the one we have adopted as a frame of reference to investigate the phenomenon of immersion. Indeed, although with the 1990s debate on Virtual Reality the semantic dimension of immersivity seems reduced only to this kind of experience (D'Orazio, 2003), we agree with GANDER when he claims that «the VR definition of immersivity says nothing about how this technological factors affect the feeling of immersion» (Gander, 1999, p. 4).

Basically, we consider immersion as the result of using immersive languages ${ }^{47}$ rather than immersive technologies. For this reason, our research focuses on the hybridizations of languages and codes resulting from multimedia convergence (Taiuti, 2005) with the aim of defining and developing communication formats able to generate this kind of cognitive and perceptual immersion by means of the combination, overlapping and blending of different media.

\subsection{Transmedia communication systems to understand and experience a place}

In the previous section we have seen how it's fundamental to present a place through different tools able to show the several peculiarities of a local reality.

\footnotetext{
46 'Aesthetics' understood as the science of sensible knowledge, according to Baumgartens's definition of scientia cognitionis sensitivae.

${ }^{47}$ the term "languages" is here understood as the way contents are displayed.
} 
A territory can be considered as a complex system and often we need a large amount of contents in order to narrate its identity. In order to find the right way to narrate the place identity we need to take a closer look at all the aspects that we want to represent (historical, morphological, socio-cultural, etc.) and define how to communicate the different information: the content has to be narrated through the right language and the right media.

Furthermore, the main aim of a communication system is to lead a strong "experience". A new toolset and new techniques are necessary to reach and engage audiences in the digital age. For this reason, we have to design the specific role of every part of the communication systems in order to catch the user attention and make accessible the right information at the right time.

We found in transmedia systems and transmedia storytelling the right choice because of their communicative qualities. They respond to the request of users to have an immersive experience that leads interactive and impactful narrations (Phillips, 2010). Transmedia communication strategies, mostly applied for movie launch and brand communication, are instead here used in order to communicate the identity of urban environment.

We want to offer an integrated and overlapping sense of experience (Jenkins, 2006) able to increase the relationship between visitors and the environment. Narrations need to be accessible through an array of media platforms, and the story must be designed to play to the strengths of the platform (STARLIGHT RUNNER ENTERTAINMENT).

The experience of the users has to evolve at every step, taking advantage from the specificity of each device. In order to do that we need to define a design process that has a strategic management of different media to achieve different objectives.

We have divided the user experience primarily in three stages: a pre-experience of the place, the exploration itself, and the post-experience (Calabi et al., 2013)

During the pre-experience the user comes into contact with media that offer immersive representations of the places enticing the user to a direct contact.

Mainly we can design a pre-experience through media such as web-based platforms and paper artefacts.

The exploration's moment is essential to create a strong relationship between the user and places. It has to be supported by media that can offer a high interaction level. An example are the mobile devices or installations that provide timely information directly on site.

In order to build new visions of a specific place it is also important to collect bottom-up feedbacks from of the users and involving them in the creation of new shared stories. This is fundamental to building a post-experience that will not get exhausted after the places' exploration. Social media and participative archives are the main tools and media that we can use to share and collect in real-time stories, images and memories.

What we want to present here is a methodology able to design innovative transmedia integrated systems for the communication of places that can offer a specific contents' distribution on different media.

Communicative systems have to present several layers of access, therefore, our aim is to offer contents in order to foster audience engagement. So the visitors and citizens become a knowledge community, where users can exchange ideas and clues with each other. We want to design immersive and engaging communication experiences. 


\section{Methods}

The communication context previously described is constantly evolving; new hybrid formats will arise and, in their turn, they will entail further linguistic transformations and opportunities to engage with content. Consequently, the setting of a theoretical ground is quite challenging and requires specific skills to bridge the gap between theory and practice.

From our perspective, design can provide a key contribution in this field because its main expertise consists in the ability of extracting the tacit knowledge that lies behind practice, to transform it in replicable models which can be used to disseminate cultural content and communicate 'landscapes'. For this reason, our approach is basically phenomenological; we start from the analysis of the state-of-the-art in order to understand and identify which are the tools at our disposal and develop replicable models (formats) that can be used in the design activity. This is the transforming function of design, which suggests methods to convert intangible knowledge (cultural content) into replicable tangible solutions (communication formats and systems).

Part of our research activity consists in developing and refining a design method (a process) which is continuously tested and refined through research - both theoretical (Chalabi and Chiodo, 2014) and applied (Scuri and Calabi, 2015) - and didactic activity.

Basically, our method consists in three main steps:

\subsection{Phase one: analyzing the territory}

The first step consists in collecting and analyzing all the contents (documents, pictures, etc.) that describe the main features and resources of the place we have to represent. This work, both qualitative and quantitative, aims to build a visual map of the contents (stories, traditions, socio-cultural habits, natural characters) which together describe the local heritage and identity. These content are then grouped in thematic categories and analyzed in order to understand and identify: a) hierarchies (their relevance in representing the local identity); b) typologies of media available to represent them (texts, images, videos, etc.); c) their main communication function - predictive, informative or directive (Giannitrapani, 2010) and consequently, when it would be more interesting for the audience to get in touch with them (e.g. before the visit in order to acquire some historical information that can be useful to understand what they will see once on-site) .

\subsection{Phase two: looking at the state of the art}

Once realized the map of territorial contents, we start to look at the-state-of-the-art in order to identify the formats and languages most suitable to provide and represent the contents gathered. The case studies analysis is grounded on a comprehensive investigation carried out between 2010 and 2013 by ELISA CHIODO (2013), which resulted in the development of a systematic and upgradeable tool - The Observatory - that collects and organizes several examples of projects (best practices) for the communication of territory. After this experience, we are continuously updating and extending the collection which still serves us as a tool in the research and design activities.

\subsection{Phase three: design the communication system}

The last phase is the core of the design transformative function as it consists in the development of the communication system - that is to say, it consists in mixing the design "ingredients" (contents, media and languages) to transform them in tangible solutions able to represent and provide cultural contents in the more effective way possible. This work of design is still part of the research process because it allows us to assess and refine the theoretical findings through the design practice (Laurel, 2003). 
As stated above, we argue that the value of communication design consists in the ability of transforming the tacit knowledge of practice into replicable formats and models that can be used to support design activity and disseminate knowledge. This transformative process involves two kind of knowledge: on the one hand, the intangible knowledge related to territories (local identities and cultural heritage), which must be transformed ("translated") into other forms in order to be comprehensible. On the other hand, there is the specific knowledge of design, which is basically methodological and results in the development of new design tools.

Basically, the contribution of communication design for the promotion of cultural heritage and the enhancement of local identity consists in developing formats and models that exploit different media channels and technologies in order to shape and disseminate intangible culture, as well as to foster the understanding of territorial resources (not only physical but also and especially socio-cultural).

In the next section we will present a didactic experience with a class of MSc students in Communication Design in order to better explain the transformative function of design and describe our research method.

\section{4. "Microcosmi d'autore. Luoghi e percorsi nella capitale dell'editoria": a didactic experience}

The design process previously described drove the work made in the last semester by the students of the course Laboratorio di Sintesi Finale at Politecnico di Milano. The assignment, titled Microcosmi d'autore. Luoghi e percorsi nella capitale dell'editoria (Authorial microcosms. Places and paths in the publishing capital $^{48}$ ), was to design a transmedia communication system for exploring the city of Milan through literary paths based on the work of some well-known writers whose lives and/or stories are strictly connected with the city. Their goal was to create a complex mixing of media, languages and medium, in order to engage users on different channels, foster the exploration of the city and support the development of new knowledge about its identity.

To reach this goal, they were divided in teams and assigned to a specific author. As first step, each team analyzed the author's works and realized a map to represent places narrated and content available to describe them (textual descriptions, images, video, etc.). They used this map to identify possible thematic paths for exploring the city from the specific view point of the author.

The second step was to carry out a case studies analysis. Each team analized different kind of communication projects (e.g. web documentaries, literary maps, geo-located content applications, installations and social media campaigns) to find the most suitable media and languages to represent their paths and the contents gathered.

One of the team worked on Alberto Savinio, the younger brother of the 'metaphysical' painter Giorgio de Chirico. He was a very eclectic person, not only a painter but also writer, musician, journalist, essayist, playwright, set designer and composer. The students focused on the book Ascolto il tuo cuore, città (1984), where Savinio describes the unknown side of Milan through a combination of dreamlike visions and real events. Here, the personality of the author emerges clearly in the vivid and detailed descriptions he makes of a city transfigured by his look. Therefore, they decided to pivot the project, titled Divagando. La Milano di Alberto Savinio, on the dichotomy between realism and surrealism, that results in a sensorially rich immersive experience.

\footnotetext{
${ }^{48}$ Milan was the "city of book" in 2015.
} 
Translating place identity into transmedia communication systems: Communication design process and methods.

The interesting aspect of this work consists in the impactful visual style that characterize all of the medium involved in the transmedia system. On the website users can virtually explore some of the places described by Savinio starting from an interactive panoramic which presents a collage of locations and environments (Figure 1). From this main page, the user can choose a place and start the experience. All the places are presented through a set of tools (Figure 2), which were identified by the case studies analysis: interactive walkthroughs, 360 degree panoramic photos, soundscapes and impactful illustrations.

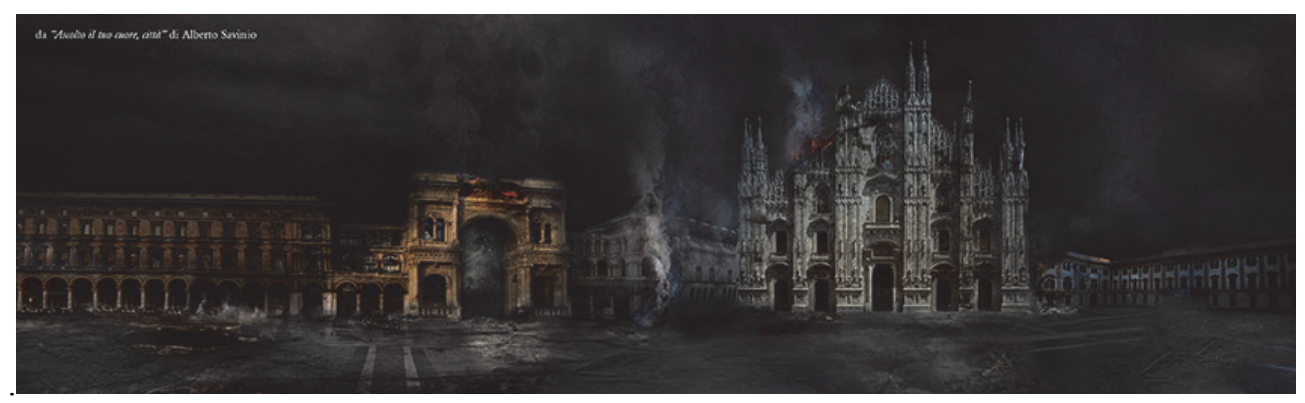

Fig. 1 The interactive panoramic which shows a collage of locations and environments described by Savinio

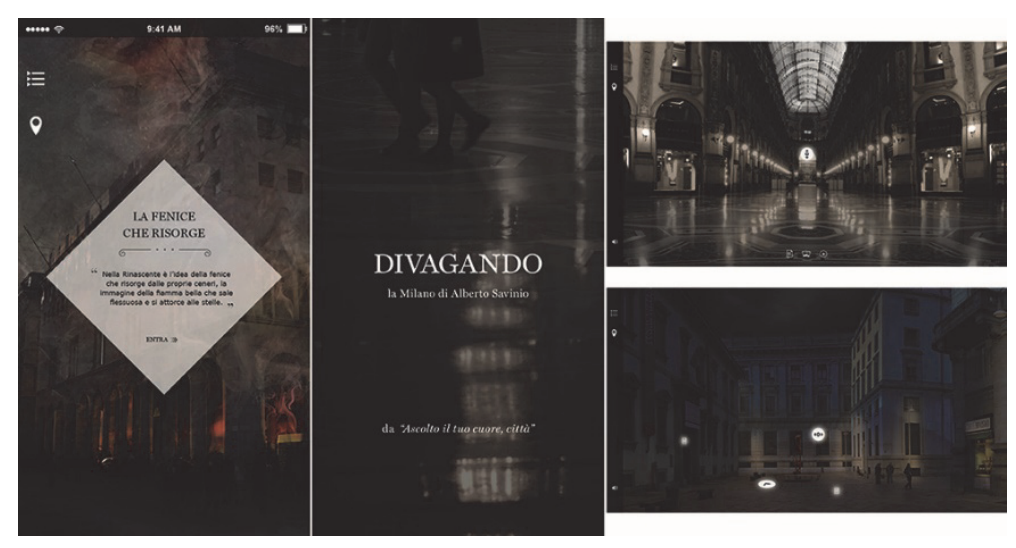

Fig. 2 Some screenshots of the mobile application and web platform

To enrich the on-site exploration, the team designed also a mobile application that guides users along a path between the statues described by Savinio. In his book the author presents these pieces of art as ghosts; as the witnesses survived to the bombings of the WWII. Each statue tells a story with its own voice and perspective; it describes how the city was before the war and also the deep changes in the urban landscape followed.

Another project, that well represents the third and last phase of the design process previously described, is Prospettiva Scerbanenco (Scerbanenco's Perspective) that represents the city of Milan through the point of view of Giorgio Scerbanenco.

Scerbanenco was an Italian journalist and writer born in Ukraine. He worked as a freelance writer for many Italian magazines as Corriere della Sera before becoming a novelist. Scerbanenco is famous for his crime and noir stories, and the strong and realistic writing style used to describe the city of Milan and its inhabitants (from the low and middle bourgeoisie to weak people like criminals and prostitutes). 
The project relies on a strong transmedia strategy that involves several media (Figure 3): a mobile application for tablet, the main social media (as Facebook and Instagram), a collection of printed fanzines and also different forms of outdoor advertising (from posters to installations).

All the media are strictly connected to each other and designed to follow a specific timetable that drives the user from the pre- to the post-experience. The temporary installations, placed in the location described in the author books, are thought to be launched concurrently with the Scerbanenco Prize. There, the user can find some copy of the printed fanzines that provide in-depth descriptions of the socio-cultural dimension of Milan during the Sixties and Seventies, through a collection of original newspaper articles. Fanzines and installations link the user to the core of the transmedia system: the mobile application, which is a combination between a digital magazine and a storymap. It guides the users into the Scerbanenco's world through three thematic paths connected to a specific character (a prostitute, a Milanese middle-class, and a criminal kid). The user can choose between these paths and access several stories which are told by means of photos, animations and some interactive multimedia packages.

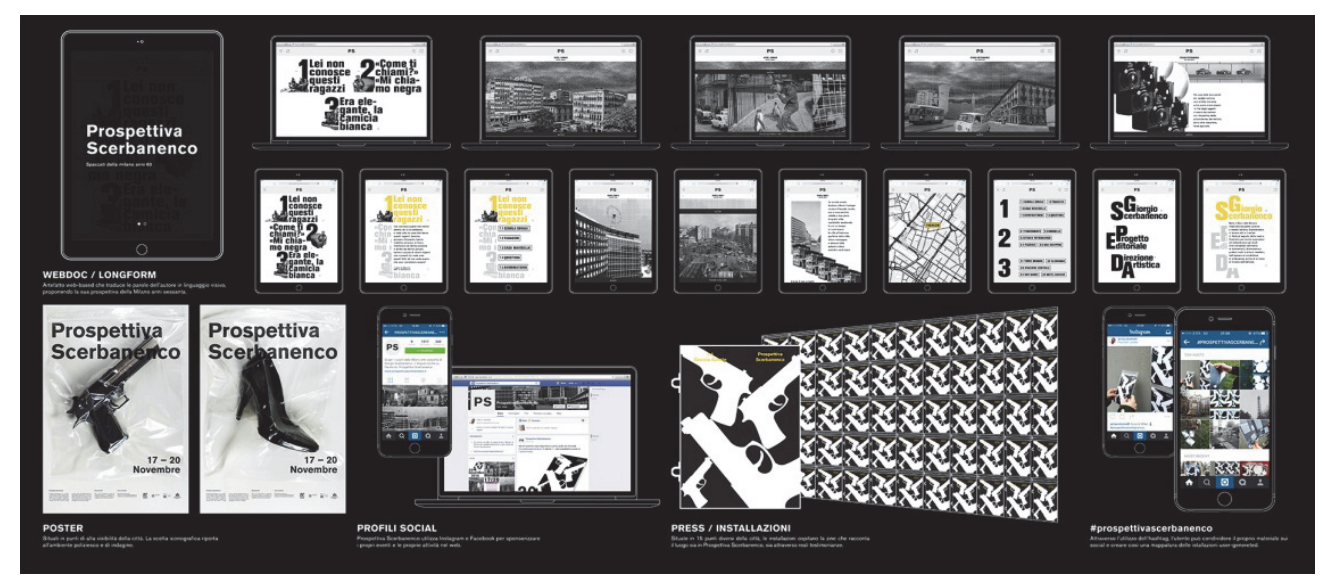

Fig. 3 The media involved in the project

The social media (Facebook and Instagram) are used to support and disseminate the communication system. On the one hand, they are linked in different ways to posters, temporary installations and fanzines, playing a role in the pre-experience and during the exploration on-site. On the other hand, they take part in the post-experience because push users to leave comments and feedback about their personal experience in real time. Prospettiva Scerbanenco is therefore a good example of using an integrated system of media to offer several accesses to a large amount of information, as well as to provide users with different opportunities to be engaged with contents.

\section{Conclusions}

Our aim, as communication designers and researchers, is to find out and develop replicable solutions (formats and models) able to enhance the intangible aspects of a local dimension and meet people's needs and interests as well (that is to say, their desire of experiencing and engaging with a territory). To this aim, great emphasis should be put on the transformative function of design that lies in the ability of translating and transferring intangible elements, like the memories of citizens, into digital products and communication systems. In order to describe this transformative process, we have presented our research 
methodology and an example of its application, focusing on the designer's ability of experimenting with technologies, media and languages (the tacit knowledge that lies in the design practice) to increase people's understanding and engagement with a given place.

We argue that the transforming function of design serves as a bridge that allows people to access and understand the system of intangible aspects that characterize the sociocultural dimension of a place. This transformative process involves two kind of knowledge: on the one hand, the intangible knowledge related to territories, which must be transformed ("translated") into other forms in order to be comprehensible. On the other hand, there is the specific knowledge of design, which is basically methodological and is part of the process itself.

\section{Acknowledgements}

Divagando, la Milano di Alberto Savinio and Prospettiva Scerbanenco, are two of the projects realized by a class of MSc students in Communication Design from Politecnico di Milano, as final result of the course Laboratorio di Sintesi Finale 2015/16.

The authors gratefully acknowledge Professors Giovanni Baule (responsible for the course), Vincenzo D'Abbraccio and Marco Quaggiotto. They would also like to thank the authors of the projects mentioned: Fargnoli Alessandra, Accardo Alessandra, Fontana Marta, Da Costa Silva Ana Raquel and Mihaylova Adelina (Divagando, la Milano di Alberto Savinio), and Castelli Giulia, Colonnelli Anna, Granello Martina and Losa Mattia (Prospettiva Scerbanenco). In addition, special thanks to Raffaella Bruno for her collaboration in the didactic activity.

\section{References}

BAUMGARTEN, A.G. (2000). L'Estetica, Palermo: Aesthetica Edizioni.

CALABI, D., CHIODO, E., and SCURI, S., (2013). "Representing the identity of urban spaces. The application of semiotic models on Communication Design Formats" in INTED2013 Proceedings (4-5 March 2013. Valencia) Valencia: IATED press. 3153-3158.

CALABI, D., and CHIODO, E. (2014). "Communication Design for Urban Environment: the Observatory" in International Advanced Design Cultures. Proceedings of the 5th International Forum of Design as a Process (18-20 Sptember 2014. Guadalajara) Mexico City: Porrúa Print. 374-380.

CHIODO, E. (2013). Communication Design for urban environment. The Design Observatory. PhD Thesis. Milano: Politecnico di Milano, <http://hdl.handle.net/10589/74246> [See: May 6, 2016].

COUNCIL OF EUROPE (2000). European Landscape Convention and reference documents. $<$ https://rm.coe.int/CoERMPublicCommonSearchServices/DisplayDCTMContent?documentId=09000016802f80c6> [See: April 16, 2016].

D’ORAZIO, F. (2003). "Immersione" in Abruzzese, A. Lessico della comunicazione. Roma : Meltemi.

EUROPEAN COMMISSION (2013). Work Programme 2014-2015 Europe in a changing world - inclusive, innovative and reflective Societies.

$<$ http://ec.europa.eu/research/participants/data/ref/h2020/wp/2014_2015/main/h2020-wp1415-societies_en.pdf> [See: January 7, 2015].

FAGNONI, R. (2004). "Mediterraneo del design | Mediterranean of design" in Fagnoni, R., Gambaro, P., Vannicola, C. Medesign forme del Mediterraneo. Firenze: Alinea.

FORLANI, F. (2004). Esperienze, marketing e territorio: Uno schema logico per l'analisi e la gestione dei sistemi d'offerta turistica territoriali. $\mathrm{PhD}$ Thesis. Genova: Università degli Studi di Genova, $<$ http://www.academia.edu/5614024/Esperienze_Marketing_e_Territorio > [See: May 6, 2015]. 
GANDER, P. (1999). "Two myths about immersion in new storytelling media" in Lund University Cognitive Studies $80<\mathrm{http}: / /$ www.pierregander.com/research/two_myths_about_immersion.pdf $>$ [See: March 12, 2015].

GIANNITRAPANI, A. (2010). Viaggiare: istruzioni per l'uso. Semiotica delle guide turistiche. Pisa: Edizioni ETS.

GIFREU, A. (2011). "The interactive multimedia documentary as a discourse on interactive non-fiction: for a proposal of the definition and categorisation of the emerging genre" in Hypertext.net, issue 9. $<$ https://www.upf.edu/hipertextnet/en/numero-9/interactive-multimedia.html > [See: July 3, 2015].

GRABOWICZ, P., HERNANDEZ, R., RUE, J. (2014). "Tutorial: Taxonomy Of Digital Story Packages". $<$ https://multimedia.journalism.berkeley.edu/tutorials/taxonomy-digital-story-packages/> [See: July 3, 2015].

GRIFFERO, T., (2010) "Dal bello all'atmosferico: un'estetica «dal punto di vista pragmatico»" in Böhme, G. Atmosfere, estasi, messe in scena: L'estetica come teoria generale della percezione. Milano: Christian Marinotti.

JENKINS, H. (2006). Convergence culture: where old and new media collide. New York: New York University Press.

JULLIER, L. (1997). L'écran post-moderne: un cinéma de l'allusion et du feu d'artifice. Paris: Editions L'Harmattan.

LASSILA-MERISALO, M. (2014). "Story First-Publishing Narrative Long-Form Journalism in Digital Environments" in Journal of Magazine \& New Media Research, volume 15, issue 2, pp. 1-15.

LAUREL, B. (2003). Design Research: Methods and Perspectives. Cambridge: MIT Press.

MACCANNELL, D. (1973). "Staged authenticity: Arrangements of social space in tourist settings" in American journal of Sociology, pp. 589-603.

MANZINI, E. (2004). "Un localismo cosmopolita | A cosmopolitan localism" in Fagnoni, R., Gambaro, P., Vannicola, C. Medesign forme del Mediterraneo. Firenze: Alinea.

MAOZ, D. (2006). "The mutual gaze" in Annals of Tourism Research, vol. 33, issue 1, pp. 221-239.

MITCHELL, N., RÖSSLER, M. and TRICAUD, P-M. (2009). World Heritage Cultural Landscapes: A Handbook for Conservation and Management. Paris: UNESCO World Heritage Centre. $<$ http://whc.unesco.org/documents/publi_wh_papers_26_en.pdf> [See: February 20, 2015].

MURRAY, J.H. (1997). Hamlet on the Holodeck - The Future of Narrative in Cyberspace. New York: The Free Press.

ORTOLEVA, P. (2009). Il secolo dei media. Riti, abitudini, mitologie. Milano: Il Saggiatore.

PHILLIPS, S. (2010). "Transmedia. What we've all been waiting for?" in License! Global, volume 13, issue 9, p. 10.

PINE, J. B., and GILMORE, J.H. (1999). The Experience Economy. Boston: Harvard Business School Press.

RICHARDS, G. (2014). "Cultural Tourism 3.0: The future of urban tourism in Europe? " in Garibaldi, R. Il turismo culturale europeo: Città ri-visitate. Nuove idee e forme di turismo culturale. Milano: Franco Angeli.

SAVINIO, A. (1984). Ascolto il tuo cuore, città. Milano: Adelphi.

SCURI, S., and CALABI, D. (2015). "Communication design for accessing cultural landscape - Design de Comunicação para o acesso à paisagem cultural" in Strategic Design Research Journal, volume 8, issue 1, pp. 29-35.

SLATER, M. (2003). "A note on presence terminology" in Presence connect, vol. 3, issu 3, pp. 1-5.

STARLIGHT RUNNER ENTERTAINMENT. Transmedia Services. Starlight Runner Entertainment background \& transmedia production primer. $<\mathrm{http}: / /$ www.starlightrunner.com/transmedia $>$ [See: March 6, 2016].

TAIUTI, L. (2005). Multimedia: l'incrocio dei linguaggi comunicativi. Roma: Meltemi.

UNESCO (2013). Operational Guidelines for the Implementation of the World Heritage Convention. $<$ http://whc.unesco.org/archive/opguide13-en.pdf $>$ [See: April 26, 2015].

ZERBA, E. (2004). "Redefining Multimedia Toward A More Packaged Journalism Online". In 5th International Symposium on Online Journalism (April 2004. Austin, Texas). Available at $<$ https://goo.gl/jI4Kwp $>$ [See: February $25,2016]$. 